\title{
REHABILITATION AFTER FRACTURES OF THE SHAFT OF THE FEMUR
}

\author{
P. J. R. Nichols, Royal Air Force
}

From the Royal Air Force Medical Rehabilitation Unit, Headley Court, Epsom, England

Because most Royal Air Force patients with fractures of the lower limb are treated at Medical Rehabilitation Units the methods of treatment and assessment are standardised, and it is possible to compare the results of different methods of treatment of the fractures. Such studies have already been made for fractures of the lower leg (Nichols and Parish $1959 a$ and $b$ ). This paper reports a study of the results of fractures of the shaft of the femur, and of the factors that affect the result.

\section{CLINICAL MATERIAL AND METHODS OF PRIMARY TREATMENT}

A total of 181 patients has been studied (Table I).

TABLE I

Age and Causes of Fracture

\begin{tabular}{|c|c|c|c|}
\hline$\underset{(\text { years) }}{\text { Age }}$ & Percentage & Cause of fracture & Percentage \\
\hline Under 20 & 32 & Motor-cycle accident & 65 \\
\hline $20-30$. & 61 & Other road accident & 19 \\
\hline & & Soccer . & 1 \\
\hline $30-40$ & 5 & Other sport & 1 \\
\hline Over 40 & 2 & On duty & 4 \\
\hline
\end{tabular}

TABLE II

Methods of TREATMENT

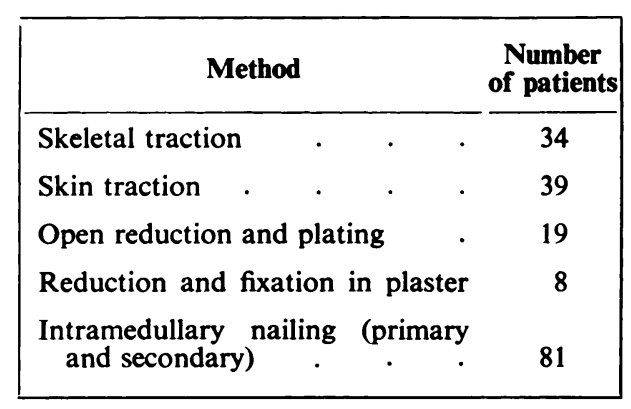

Initial treatment-The patients had been treated initially at many different hospitals, service and civilian, both in this country and overseas. Six methods of treatment had been used (Table II).

Intramedullary nailing had been done either as primary treatment within the first three weeks after injury, or as secondary treatment for failure of union or for persistent deformity or for both. The numbers in each group were about equal. 
Rehabilitation-The patients started with quadriceps contractions and went on to exercises in physiotherapy departments, progressing as soon as fracture union was adequate to active movements of the knee without bearing weight. They were usually transferred to the rehabilitation unit when they were taking some weight or had had a caliper fitted and were thus ready for more concentrated physical treatment.

The rehabilitation programme in the early stages included: 1 ) instruction and practice in the correct use of crutches and calipers; 2) quadriceps setting exercises progressing to nonweight-bearing knee movements in classes; 3) individual instruction in re-education of the quadriceps for patients with defective active extension of the knee; 4) treatment in the pool to start weight bearing and to help movement of the knee.

As union progressed, re-education in walking and more powerful weight-bearing exercises were introduced. Particular attention was paid to regaining full active extension of the knee. When necessary, compensation for shortening was effected by raising the sole and heel: when shortening was between a half and one inch a sole and heel raise of half an inch was given; when it was more than this a tapered raise was provided (Nichols 1960).

\section{RESULTS}

Clinical union-The average time between injury and recorded union-that is, union judged adequate both clinically and radiologically-was nineteen weeks. Thirty-one per cent of fractures were judged united within sixteen weeks.

Duration of total disability-In the armed services the final assessment and disposal are reasonably well standardised, so that the total time from injury to return to duty or civilian employment may be used for assessing the value of the various methods of treatment. In this series 72 per cent of the patients returned to duty and 28 per cent were invalided.

The number of patients invalided is a result of the time-limit imposed on the treatment of national servicemen rather than an indication of the quality of the results achieved. Most of those invalided remained under full in-patient treatment until they were fit enough for civilian employment or for retraining. Fifty per cent of the patients invalided had fractures of the patella or of the tibia in the same limb.

Fracture of the shaft of the femur involved a period of disability of nine or ten months for all patients except those treated early by intramedullary nailing, who were on average off duty for less than seven months (Table III).

TABLE III

Average Duration of Total Disability Related to

INITIAL TREATMENT

\begin{tabular}{|c|c|}
\hline Method of treatment & $\begin{array}{c}\text { Duration of } \\
\text { total disability } \\
\text { (weeks) }\end{array}$ \\
\hline Early intramedullary nailing . & 26 \\
\hline Skeletal traction & 38 \\
\hline Closed reduction and plaster fixation & 40 \\
\hline Skin traction & 42 \\
\hline Open reduction and plating & 42 \\
\hline
\end{tabular}

Period of mobilisation-This is the period between the time of clinical union and that of discharge from treatment. Although the period of total disability is obviously increased when union 
is slow, the period of rehabilitation is nearly the same for all patients except for those treated by early intramedullary nailing. They are spared about one month of rehabilitation (TableIV). Range of movement of the knee-The restoration of movement of the knee is one of the main problems after fracture of the femur. In the present series two-thirds of patients regained good knee movements (better than 0-90 degrees). With this range they could sit comfortably in any chair and could trot. A good range of knee movement was obtained less frequently

TABLE IV

Average Duration of Period of Mobilisation Related to Initial Treatment

\begin{tabular}{|c|c|}
\hline Method of treatment & $\begin{array}{c}\text { Duration } \\
\text { (weeks) }\end{array}$ \\
\hline Early intramedullary nailing & 11 \\
\hline Non-skeletal traction & 14 \\
\hline Skeletal traction & 15 \\
\hline Open reduction and plating & 16 \\
\hline Closed reduction and plaster fixation & 17 \\
\hline Average & 15 \\
\hline
\end{tabular}

TABLE V

Relation of Range of KNeE Movement to Method of Initial TREatment

\begin{tabular}{|lcc|}
\hline Method of treatment & $\begin{array}{c}\text { Percentage of knees } \\
\text { regaining range of } \\
\text { movement of } \\
\text { degrees or more }\end{array}$ \\
\hline Skin traction . & $\cdot$ & 41 \\
Skeletal traction &. & 51 \\
Plating . & 53 \\
Early intramedullary nailing & 78 \\
\hline
\end{tabular}

after comminuted fractures ( 58 per cent) than after simple ( 78 per cent) or compound ( 60 per cent) fractures, irrespective of whether treatment was by traction or by intramedullary nailing. Delay in union was more common in comminuted fractures than in the other groups. The range of movement obtained varied considerably with the method of initial treatment (Table V). Three out of four patients whose fractures were nailed regained a good range of knee movement; only one-half of the patients treated by other methods regained such a range.

Seventy-five per cent of patients whose fractures united in nineteen weeks or less regained a good range of knee movement; 57 per cent of those whose fractures united in twenty to twenty-four weeks, and 40 per cent of those whose fractures took more than twenty-four weeks to unite regained a good range.

Open reduction and plating was followed more often by quadriceps adherence than was any other method of initial treatment.

\section{COMPARISON OF THE RESULTS OF INTRAMEDULLARY NAILING WITH THOSE OF TREATMENT BY TRACTION}

There were four almost equal groups of patients with similar fractures and of similar age, temperament and trade who were treated respectively by skin traction, skeletal traction, early intramedullary nailing - that is, nailing done within the first three weeks after injury-and delayed intramedullary nailing.

Nineteen patients subjected to intramedullary nailing had been previously treated by skeletal traction and sixty-two had been treated by skin traction. The primary treatment had no direct effect on the result or on the time taken to achieve it. There was no difference in the rate of union or eventual result between those who had operation in the first week and those who had it in the second. After the second week, however, increasing delay before operation led to progressively longer duration of disability and progressively disappointing results.

Many of the fractures treated by delayed intramedullary nailing were those showing delay in union or other complications associated with other methods of primary treatment. 
Most of these patients had very stiff knees at the time of operation; in these the intramedullary nail was used in order to avoid further immobilisation of the knee.

Early intramedullary nailing gave the best results as regards knee movements and shortening. The results of delayed nailing were less good (Table VI).

TABLE VI

Comparison of Results of Intramedullary Nailing with those of Other Methods

\begin{tabular}{|c|c|c|c|c|}
\hline & $\begin{array}{c}\text { Early } \\
\text { intramedullary } \\
\text { nailing }\end{array}$ & $\begin{array}{c}\text { Delayed } \\
\text { intramedullary } \\
\text { nailing }\end{array}$ & $\underset{\text { Sraction }}{\text { Skin }}$ & $\begin{array}{l}\text { Skeletal } \\
\text { traction }\end{array}$ \\
\hline Number of fractures. & 46 & 35 & 39 & 34 \\
\hline Average period from injury to discharge (weeks). & 26 & 38 & 38 & 32 \\
\hline Percentage returned to duty & 87 & 57 & 68 & 94 \\
\hline Percentage regaining good range of knee movement & 78 & 43 & 51 & 41 \\
\hline Percentage with shortening & 20 & 17 & 55 & 53 \\
\hline
\end{tabular}

Comminuted fractures-Since comminution appears to be an important factor in the production of delayed union and consequent prolongation of the duration of total disability and deterioration of results, it is interesting to study the results obtained by intramedullary nailing of comminuted fractures. Four comminuted fractures were treated by early intramedullary nailing and seven were treated by delayed nailing. The average duration of disability from operation to return to duty was thirty-two weeks in both groups. Only one patient was discharged with a knee range of less than 60 degrees.

In the other twenty-seven cases of comminuted fracture the average duration of disability was thirty-seven weeks. Five patients failed to regain an adequate range of knee movement.

\section{COMPLICATIONS}

Delayed union-Union took longer than twenty-four weeks from injury or operation in 28 per cent of cases. The incidence of delayed union varied considerably with the method of initial treatment (Table VII).

TABLE VII

Relation of Delayed Union to Method of Initial Treatment

\begin{tabular}{|c|c|}
\hline Method of treatment & $\begin{array}{l}\text { Percentage of fractures taking } \\
\text { over twenty-four weeks to unite }\end{array}$ \\
\hline Early intramedullary nailing & 3 \\
\hline Skeletal traction & 30 \\
\hline Skin traction & 36 \\
\hline Plaster or splint fixation & 44 \\
\hline Open reduction and plating & 47 \\
\hline Average . & 28 \\
\hline
\end{tabular}

About one-third of the fractures treated by traction and nearly half of those treated by open reduction, plating, plaster-of-Paris or Thomas's splint took more than twenty-four weeks to unite. Early intramedullary nailing was followed by delayed union in only 3 per cent of fractures.

VOL. 45 B, NO. 1, FEBRUARY 1963

G 
These results are closely related to the type of fracture, because this usually determines the method of treatment. Although 25 per cent of both simple and compound fractures were followed by delayed union, comminution was associated with an incidence of delayed union of 35 per cent.

Stiffness of the knee-Sixteen per cent of patients regained less than 60 degrees of movement of the knee. Only 2 per cent of patients treated by early intramedullary nailing obtained less than 60 degrees of movement whereas limitation of this degree was recorded in 26 per cent of patients treated by skin traction and in 18 per cent of those treated by skeletal traction. Quadriceps adherence-Approximately 8 per cent of fractures were followed by anchorage of the quadriceps muscle severe enough to be clinically significant (Table VIII). The position of the incision used in intramedullary nailing was not found to influence the incidence of quadriceps adherence providing early mobilisation was practised.

TABLE VIII

INCIDENCE OF QUADriceps AdHerence Related to METHOD OF INITIAL TREATMENT

\begin{tabular}{|c|c|}
\hline Method of treatment & $\begin{array}{l}\text { Percentage incidence } \\
\text { of adherence }\end{array}$ \\
\hline Intramedullary nailing & 7 \\
\hline Open reduction and plating & 27 \\
\hline Skin traction . & 5 \\
\hline Skeletal traction & 3 \\
\hline Average & 8 \\
\hline
\end{tabular}

Other complications-In three cases the intramedullary nail bent, but union continued satisfactorily after the amount of weight borne was reduced. In one case the nail broke, and in three there was a tendency for the nail to extrude. One wound became infected and sequestrectomy was later required.

\section{FOLLOW-UP}

Follow-up of service patients is difficult to arrange because they may have left the service or have been posted overseas. One hundred and thirty-one of the 181 patients studied were serving in the Royal Air Force at the time of injury. In seventy-three cases the patient or his records were available for review at periods of from three to twenty-four months after discharge from the rehabilitation unit. Twenty-three patients had been released from the service with no functional disability. Twenty-four had improved sufficiently in function for their medical category to be raised, and twenty-three had not improved in function. Three had been invalided: one because of osteoarthritis, one after a plastic operation on the quadriceps, and one after an operation for equalising the length of the lower limbs.

The range of knee flexion is probably the best guide to function. In no case was it found to have deteriorated, but the chance of improvement apparently depended on the method of primary treatment. Intramedullary nailing was followed by the best results as regards early restoration of knee flexion; in addition, the range of knee flexion of patients so treated improved more often after return to duty than did that of the other groups. Most patients treated by skeletal traction continued to improve, but only 50 per cent of those treated by skin traction and 30 per cent of those treated by plating showed continued improvement.

\section{DISCUSSION}

Although accurate analysis of the results in this series is difficult because of the variation in the methods of initial treatment, certain interesting features emerge in connection with the management of femoral fractures. 
This injury involves a total period of disability averaging seven to twelve months. Even in previously fit young men it often leaves some degree of disability. Indeed, Young (1942) stated that: "A soldier who has had a fracture of the femur is unlikely to return to duty, not because of malunion or non-union of the fracture, but because of the disability resulting from stiffness of the knee joint."

Funsten and Lee (1945) assessed the average time for clinical union in fifty-four fractures of the femoral shaft as 11.2 weeks and for radiological union 30.4 weeks. Firm, safe union is unlikely to occur in less than twelve weeks and most fractures will unite in twelve to twenty-four weeks. The average time in this series was nineteen weeks. Some patients only came to the rehabilitation units because union was delayed; thus the higher incidence ( 28 per cent) of delayed union in this series is a reflection of the selection of the cases.

The two main causes of limitation of knee range are: 1) periarticular or articular adhesions and 2) adherence of the quadriceps. Both are dependent on the type of fracture, the method of reduction and the duration of immobilisation.

The low incidence of quadriceps adherence ( 8 per cent) is a tribute to early active exercises (Watson-Jones 1956), and the low incidence of a poor functional knee range (16 per cent) can be attributed to the continuation of active exercise régimes at rehabilitation units.

Probably the most important factor in achieving good results is the patient's temperament. The treatment is associated with pain and discomfort and long periods of restricted activity and monotonous exercises. The purposive, active atmosphere of the rehabilitation unit can do much to overcome these difficulties.

For many years the most favoured method of treatment has been continuous traction in some type of suspension until clinical union occurs. This technique is often associated with " unavoidable sequelae of joint stiffness, muscle atrophy and general debility" (Brav and Jeffress 1952). The results in the present series show that with full-time rehabilitation disabling joint stiffness, muscle atrophy and general debility are not inevitable sequelae of treatment by traction. At least half the patients treated in this way had 90 degrees or more of knee flexion when discharged. Our results show that skeletal traction produces better results both in speed of union and knee movements than does skin traction.

The series also demonstrates excellent results obtainable by intramedullary nailing, whether this is used as an immediate method of treatment or whether it is used as a delayed technique when other measures have in some degree failed. Intramedullary nailing has three advantages. Firstly it does away with the prolonged recumbency, the unpleasantness of nursing patients in suspension and the additional work for hospital staff, and produces better results than traditional traction techniques in less time. Secondly, it allows early mobilisation of the knee so that functional recovery can progress in parallel with clinical union. Thirdly, it can be used in the management of fractures of the shaft of the femur which have failed to unite or have united with deformity, without imposing a further period of prolonged immobilisation.

Internal fixation always adds to the difficulty of assessing union because the added stability masks mobility at the fracture site. It is sometimes tempting to rely too much on the intramedullary nail and introduce vigorous exercises and weight bearing at a relatively

early stage. In many cases the fracture line remains visible for a long time despite a mass of ensheathing callus.

\section{SUMMARY}

1. The results of rehabilitation of 181 patients with fractures of the shaft of the femur are analysed.

2. The results are mainly dependent on the severity of the fracture and the method of reduction and immobilisation. It is stressed that full-time rehabilitation can help to attain the best results. 3. The advantages of intramedullary nailing of fractures of the femoral shaft are discussed.

VOL. 45 B, NO. 1, FEBRUARY 1963 
My thanks are due to all the Royal Air Force Orthopaedic Specialists and to the staffs of the Royal Air Force Medical Rehabilitation Units for their interest and cooperation. I am particularly grateful to $\mathrm{Mr} \mathrm{H}$. OsmondClarke, Air Commodore L. McK. Crooks, Group Captain D. M. Keir and Wing Commander C. B. Wynn Parry for their help and advice in the preparation of this paper and to the Director General of Medical Services of the Royal Air Force for permission to publish.

\section{REFERENCES}

Brav, E. A., and Jefresss, V. H. (1952): Fractures of the Femoral Shaft. American Journal of Surgery, 84, 16. Funsten, R. V., and LEE, R. W. (1945): Healing Time in Fractures of the Shafts of the Tibia and Femur. Journal of Bone and Joint Surgery, 27, 395.

Nichols, P. J. R. (1960): Short-leg Syndrome. British Medical Journal, i, 1,863.

Nichols, P. J. R., and Parish, J. G. (1959a): Rehabilitation of Fractures of the Shafts of the Tibia and Fibula. Annals of Physical Medicine, $5,73$.

Nichols, P. J. R., and PARISH, J. G. (1959b): Rehabilitation of Malleolar Fractures of the Tibia and Fibula. Annals of Physical Medicine, 5, 128.

Watson-Jones, Sir R. (1956): Fractures and Joint Injuries. Fourth edition. Vol. 2, p. 736. Edinburgh and London: E. \& S. Livingstone Ltd.

Young, R. H. (1942): The Prophylaxis and Treatment of the Stiff Knee Following Fracture of the Femur. Proceedings of the Royal Society of Medicine (Section of Orthopaedics), 35, 716. 